\title{
Autobiographical narratives in the elderly with neurocognitive disorder: an integrative literature review
}

\author{
Ana Paula Machado Goyano Mac-Kay ${ }^{1}$ \\ https://orcid.org/0000-0002-8116-3308 \\ Melissa Barrera ${ }^{1}$ \\ https://orcid.org/0000-0002-2565-9018 \\ Camila Córdova ${ }^{1}$ \\ https://orcid.org/0000-0002-7205-8880 \\ Romina Olivares ${ }^{1}$ \\ https://orcid.org/0000-0003-3531-5507 \\ Daniela Vásquez ${ }^{1}$ \\ https://orcid.org/0000-0003-2350-9654
}

Universidad Santo Tomás, Facultad de Salud, Viña del Mar, Chile.

Conflict of interests: Nonexistent

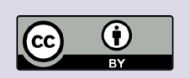

Received on: February 27, 2020

Accepted on: July 9, 2020

Corresponding address:

Ana Paula M. G. Mac-Kay

Avenida Uno Norte, 3041

Código Postal: 2320000 - Viña del Mar -

Chile

E-mail: apmackay@gmail.com;

anamachadogoyanoma@santotomas.cl

\section{ABSTRACT}

Objective: to carry out an integrative review of the literature on autobiographical narratives as a discursive activity in the older adult with neurocognitive disorder.

Methods: a descriptive study that covered the Scopus, SciELO, PubMed, and Science Direct databases, from 2009 to 2019, using the keywords autobiographical, narrative, dementia, reminiscence, the elderly, and the Boolean operator. A narrative synthesis was adopted considering the characteristics of the clinical, and methodological heterogeneity of the studies.

Results: the results included 3 articles published between 2012 and 2018, in the English language, from the United Kingdom, Brazil, and Argentina, which highlighted the autobiographical narratives. Although in a strict sense they did not present the narrative as a specific objective of the autobiographical study, they did provide interesting and related data which justified their inclusion.

Conclusion: it is observed that the literature researched presents a limited number of articles, adressing the autobiographical narrative as a discursive activity in the elderly with neurocognitive disorder.

Keywords: Autobiography; Narration; Dementia; Mental Recall; Aged 


\section{INTRODUCTION}

Over the years, the human organism goes through a natural physiological decline, which affects cognitive abilities and intervenes in communication skills ${ }^{1,2}$. Among the diversity of pathologies associated with aging, with a global prevalence between $15 \%$ to $20 \%$, are neurocognitive disorders (NCD), which are presented as mild neurocognitive disorder (mild NCD) and major neurocognitive disorder (major NCD). The symptomatic aspects of its diagnosis are disorders in attention, executive function, learning, memory, language, visuoperceptive and visuoconstructive functions, and social cognition ${ }^{3}$; consequences of the functionality of the user and the degree of intensity of the symptoms characterize the type of major or minor neurocognitive disorder. The Diagnostic and Statistical Manual of Mental Disorders (DSM V), describes its diagnostic criteria. (Figures 1 and 2).

A- Evidence of a modest cognitive decline from a previous level of higher performance in one or more of one of the referred cognitive domains:

1- Concern of the individual, an informed third party or the physician regarding a modest decline in cognitive functions.

2- Decline in neuropsychological performance, implying a performance in tests of the range of one to two standard deviations below what is expected in the regulated neuropsychological evaluation or before an equivalent clinical evaluation

B- Cognitive deficits are insufficient to interfere with independence (e.g., instrumental activities of daily life, complex tasks such as managing medication or money), it may be necessary to try harder, use compensatory strategies or make an accommodation to maintain independence.

C- Cognitive deficits do not occur exclusively in the context of a delirium.

D- Cognitive deficits are not primarily attributable to the presence of other mental disorders (e.g., major depressive disorder, schizophrenia)

Figure 1. DSM-5 diagnostic criteria for mild neurocognitive disorder
A- Evidence of a substantial cognitive decline from a previous level of higher performance in one or more of the referred cognitive domains:

1- Concern of the individual, an informed third party or the physician regarding a substantial decline in cognitive functions

2- Decline in neuropsychological performance, implying a performance in tests of the range of two or more standard deviations below what is expected in the regulated neuropsychological evaluation or before an equivalent clinical evaluation

B- Cognitive deficits are sufficient to interfere with independence (e.g., they require assistance for instrumental activities of daily life, complex tasks such as managing medication or money)

C- Cognitive deficits do not occur exclusively in the context of a delirium.

D- Cognitive deficits are not primarily attributable to the presence of other mental disorders (e.g., major depressive disorder, schizophrenia)

Figure 2. DSM-5 diagnostic criteria for major neurocognitive disorder

Mild NCD is a syndrome that comprises of a group of cognitive deficit symptoms above what is expected at a certain age in a given culture ${ }^{4,5}$. It shares risk factors with major NDC such as age, sex, educational level, genetic load and the presence of depressive disorders ${ }^{5,6}$. Alterations in cognitive functions such as language, temporal and spatial orientation, memory and visual perception ${ }^{7,8}$, can manifest in mild NCD, and is often considered a possible precursor to dementia (as an intermediate stage between normal aging and dementia) mainly for Alzheimer type dementia9. A person with compatible symptoms may eventually develop some type of dementia, remain stable or return to normal cognitive functioning ${ }^{3,7}$. According to the type and number of cognitive affected domains mild NCD is classified in mild NCD - single domain (memory), amnesic and non amnesic, and mild NCD - multiple domains, amnesic and non amnesic ${ }^{7}$. Major NCD is distinguished by its relationship to a disease (vascular disease, Alzheimer's disease, Lewy body disease and frontotemporal lobe degeneration among others $)^{3}$, and presents specific signs that cause social, work, and family dysfunction, dependence and significant loss of cognitive abilities ${ }^{10}$.

The effects of communication, language, and cognition physiological decline affect oral and written discourse expression, cognitive response speed, the processing of information that acts in the capacity of text construction, and memory ${ }^{1,10,11}$. 
Discourse activities are ways of using the speaker's availablity at the time of speech production ${ }^{11}$. Narrating is a discursive activity that puts into action cognitive and linguistic skills such as organization, sequencing, topicalization (which ensures the progression of the discourse), and adaptation for the development of narrative activity in the context of language production ${ }^{12}$. Likewise, narration is a task that mobilizes cognitive functioning due to the ordering of experiences and knowledge that have their own functional principles and specific refining criteria $^{13}$. Typically, human capacity to tell what was lived, coordinated with the necessary means of conceptualization, organizes forms of structuring the experiences. It also determines which aspects could be expressed, the ways of accomplishment, and which assignment of meaning is feasible ${ }^{13}$. This task involves both the complex resources of working and episodic memories and strategies directed to particular objectives and meanings, which lower the overload of working memory and activate the episodic memory, promoting an adequate development of narrative activity's adaptation within the production context ${ }^{13}$. Narrative context production must be considered in conjunction with the whole narrative process. Together, context and text contribute to the construction of senses because the discursive structure includes an established system of ideas, concepts, and ways of thinking ${ }^{14,15}$.

An autobiographical narrative (AN) is identified as a life story that tells the relevant events in the first person, presented in a chronological manner; however, on some occasions, the person usually jumps from the past to the present or future. This form of storytelling does not rigorously follow a linear structure ${ }^{16}$.

Personal identity and memory are usually relevant topics that provide the necessary information for understanding linguistic and communicative development processes in aging. Under this perspective, AN offers the space for the incorporation of time (past, present, and future) integrated with feelings, facts, and emotions $^{17}$.

The AN depends on the narrator's perspective and discursive skills. It is a text that reveals the subject's linguistic-discursive strategies ${ }^{17}$ and, therefore, it is continuously affected by the interpretation of either the subject himself or his interlocutor ${ }^{18}$. In this sense, Labov ${ }^{19}$ proposes as an essential issue the understanding of how people assemble the linguistic-narrative structures to achieve a purpose. One interesting angle of AN study is to apprehend both author's construction strategies and usage of accessible resources while creating a text. Investigations verified discursive markers, such as the content decrease and recurrent reformulations in subjects with probable NCD signs ${ }^{20,21}$. Therefore, this discursive activity may be relevant to communication and memory research among senecents ${ }^{18,20,21}$ because it allows one plausible approach to narrative gerontology 22 , to NCD understanding ${ }^{21}$, and to the organization of rehabilitation programs ${ }^{21}$.

Considering that $\mathrm{AN}$ is a locus of linguistic and communicative functioning processes' analysis, the aim of the present study was to carry out an integrative review of autobiographical narrative as a discursive activity of the older adult presented with neurocognitive disorder.

\section{METHODS}

The present study applied the integrative literature review method, with a qualitative approach of descriptive scope, to evaluate and synthesize the evidence for a finer understanding of the examined phenomenon.

To direct the study and its discussion, the following guiding question was asked: What has been published apropos autobiographical narrative as a discursive activity of the elderly with neurocognitive disorder in the past ten years, in open access journals?

The selected studies were evaluated according to the adapted criteria from PRISMA ${ }^{23}$. The search was performed using Scopus, SciELO, PubMed and Science Direct databases, during the months of July and August 2019, adopting the keywords and their Boolean combinations "and" in Spanish (Autobiografía, Narrativa, Demencia, Reminiscencia, Adultos Mayores), in Portuguese (Autobiografia, Narrativa, Demência, Reminiscência, Idoso), and in English (Autobiography, Narrative, Dementia, Reminiscence, Elderly).

The chosen publication time range was from January 2009 to July 2019, considering the following inclusion criteria: full, original and open access articles, published in Spanish, Portuguese and/or English, with main topics related to the study objective, and studies of older adults with neurocognitive disorder as part of the sample. Researches published in other languages, without correspondence to the main study topic, theoretical and systematic review articles were excluded. The data was organized according to author, year, journal, country, objective, method, and result. 


\section{LITERATURE REVIEW}

Initially, the search based on keywords retrieved from 18,867 articles published between January 2009 and July 2019. The diagram below summarizes the flow of the review.

\section{Review Flow Chart:}

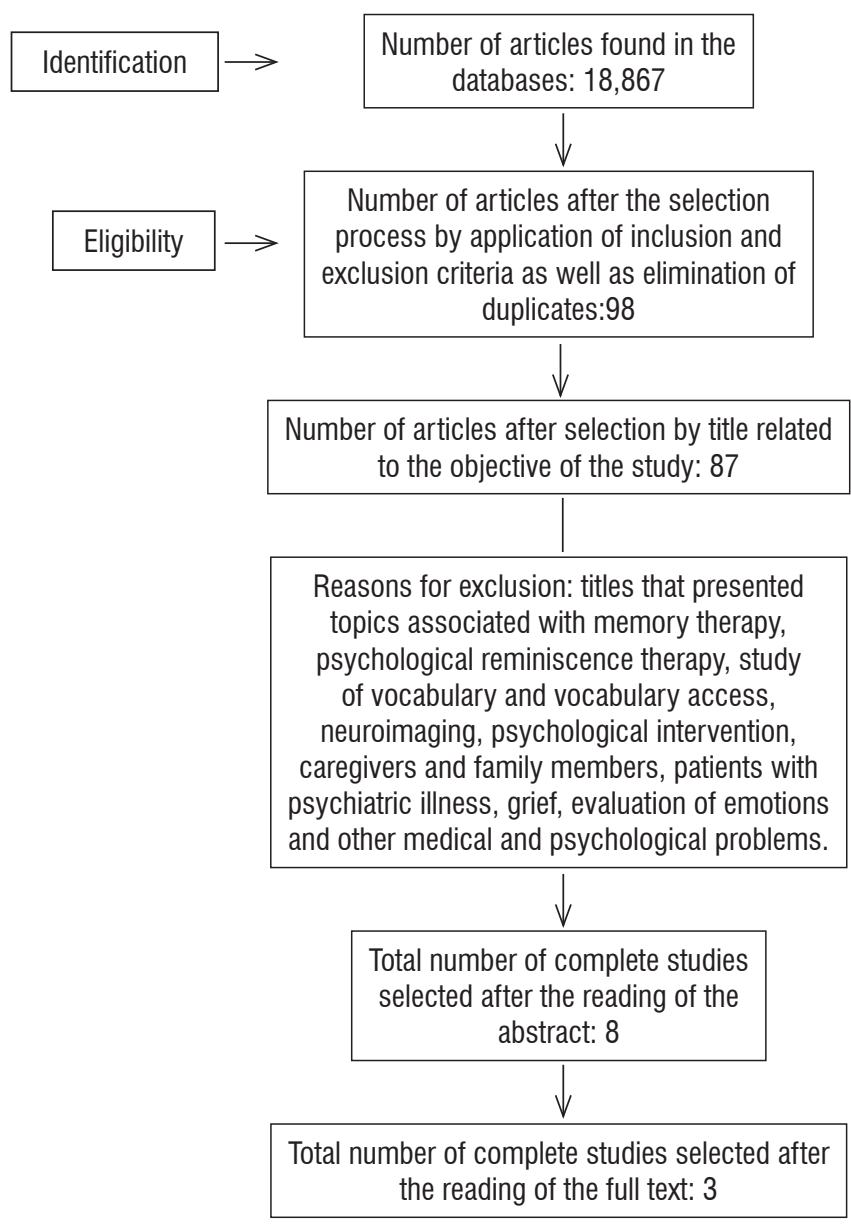

A total of 98 articles were selected for reading after the application of the inclusion and exclusion criteria and the elimination of duplicates. All researchers reviewed this process to avoid bias. Next, a selection was made by titles, when those articles presented subjects that were not relevant to the objective they were eliminated, as is clarified in the previous diagram. After reading of the abstract and verifying the presence of the central theme of the study, eight articles were chosen for complete reading. Finally, three articles, all published in English, were retrieved: one from the United Kingdom ${ }^{24}$, one from Brazil ${ }^{25}$ and one from Argentina $^{26}$. The three studies present quantitative methodology. Figure 3 provides the characteristics of the selected articles.
Although in a strict sense the three studies did not declare the discursive activity in the AN as their specific objective, they developed interesting and related aspects, which justifies their inclusion.

The United Kingdom study ${ }^{24}$ discussed the consequences of posterior cortical atrophy (PCA) in autobiographical narratives. The authors proposed that autobiographical memories are instilled with visual information that plays a prominent role in memory recovery, a fact confirmed by neuroscience evaluations ${ }^{27}$. A sample of 14 PCA patients were compared to 28 healthy subjects and 18 patients with Alzheimer's disease. The autobiographical memory was evaluated by the Autobiographical Interview ${ }^{28}$, and focused on three different periods (adolescence, adulthood, and recent time, that is, with a specific time and place in life). Results indicated that PCA patients demonstrated deficits on all visuospatial function tests, episodic memory and attention, and variable deficits of language and executive function tests. Visuospatial impairment was observed by a specific reduction in the narratives spatial-temporal and perceptual information of the PCA group. Either decreased or loss of internal and episodic details were found in the AN memories of subjects in the Alzheimer and PCA groups. These data corroborate a study on the narratives of subjects with $N C D^{21}$.

The Brazilian research ${ }^{25}$ included the use of computerized metrics to analyze coherence and failures in the expression of knowledge in the discourse of people with Alzheimer's disease and healthy subjects. Possible correlations between coherence and informational problems and cognitive performance were also investigated through language and memory assessments. The total sample of participants was 34 subjects: 18 composed the experimental group with probable Alzheimer's disease and 16 the control group without neurological or psychiatric disorders. The procedure used was the presentation of pictures of the "Little Red Riding Hood" children's story and the request to tell the story. The CohMetrix-Dementia program was selected for text analysis and it included the number of propositions and propositional relations with the following analysis criteria: global coherence, local coherence and difficulties in the expression of knowledge. Cognitive abilities were evaluated through neuropsychological tests: verbal comprehension, use of the lexical-semantic system, ability to detect semantic relationship, short-term memory, working memory, and episodic memory. The authors highlighted that the pictorial stimulus presented important challenges for 


\begin{tabular}{|c|c|c|c|}
\hline $\begin{array}{l}\text { Author/ Year/ } \\
\text { Journal / Country }\end{array}$ & Objective & Methods & Results \\
\hline $\begin{array}{l}\text { Ahmed et al., } \\
2018^{24} \\
\text { Neuroimage: } \\
\text { Clinical. } \\
\text { Reino Unido }\end{array}$ & $\begin{array}{l}\text { To examine the } \\
\text { neuroanatomical } \\
\text { characteristics } \\
\text { and substrates of } \\
\text { autobiographical memory } \\
\text { in subjects with posterior } \\
\text { cortical atrophy. }\end{array}$ & \begin{tabular}{|l|} 
Quantitative study with a sample of 60 \\
subjects: 14 with posterior cortical atrophy, \\
18 with Alzheimer's disease and 28 healthy \\
controls. All subjects responded to an \\
autobiographical interview. The groups were \\
matched for age and years of education. \\
Diagnosis was established by a behavioral \\
neurologist and neuropsychologists. \\
All 14 subjects met the consensus criteria for \\
posterior cortical atrophy, based on clinical \\
evaluation, brain imaging, and evaluation with \\
neuropsychological tests. \\
All participants were asked to provide a \\
detailed description of a personal experience \\
event that occurred at a specific time and \\
place at four different times in life: adolescence \\
(11-17 years), early adulthood (18-35 years), \\
adulthood (36-55 years) and recent time \\
(within the last year). These procedures were \\
part of an autobiographical interview protocol \\
that included a scoring matrix.
\end{tabular} & $\begin{array}{l}\text { Remote memory deterioration proved to be } \\
\text { correlated to posterior cortical atrophy, despite } \\
\text { the evidence of medial temporal lobe structures } \\
\text { relative preservation. } \\
\text { When compared to healthy controls, the group } \\
\text { with posterior cortical atrophy produced } \\
\text { narratives with specific detailed description } \\
\text { reduction related to espace, time, and } \\
\text { perceptual aspects. They also presented a } \\
\text { decrease of internal and episodic information. } \\
\text { However, these results were similar to the } \\
\text { Alzheimer's group. } \\
\text { The experimental groups displayed an } \\
\text { increasing use of tangential external details } \\
\text { while describing the episodes. } \\
\text { The study verified a remote memory } \\
\text { impairment associated with posterior cortical } \\
\text { atrophy despite the medial temporal lobe } \\
\text { structures preservation. In addition, the } \\
\text { results evidencied autobiographical memory } \\
\text { deficits that could be related to higher visual } \\
\text { processing deficits. }\end{array}$ \\
\hline $\begin{array}{l}\text { Toledo, Aluísio, } \\
\text { Borges dos } \\
\text { Santos, Brucki, } \\
\text { Trés, Oliveira \& } \\
\text { Mansur. (2018) } \\
\text { Alzheimer's } \\
\text { \& Dementia: } \\
\text { Diagnosis, } \\
\text { Assessment } \\
\text { \& Disease } \\
\text { Monitoring. } \\
\text { Brasil. }\end{array}$ & $\begin{array}{l}\text { To verify the differences } \\
\text { between subjects with mild } \\
\text { Alzheimer's disease, mild } \\
\text { cognitive impairment and } \\
\text { healthy controls in the task } \\
\text { of producing narratives, and } \\
\text { to explore } \\
\text { an innovative discourse } \\
\text { analysis computer program } \\
\text { that could identify } \\
\text { macrostructural markers } \\
\text { performance aspects and } \\
\text { help to differentiate subjects } \\
\text { at each stage. }\end{array}$ & $\begin{array}{l}\text { Quantitative study carried out on } \geq 60 \text { years } \\
\text { subjects. The sample consisted of } 60 \text { subjects, } \\
\text { divided into three groups: mild Alzheimer's } \\
\text { disease, mild amnestic cognitive impairment, } \\
\text { and healthy controls. } \\
\text { It was used the Little Red Riding Hood story } \\
\text { as stimulus, and all the collected data was } \\
\text { transcribed. The CohMetrix-Dementia program } \\
\text { was used to extract the metrics for the } \\
\text { computerized analysis. } \\
\text { Linguistic and cognitive skills were evaluated } \\
\text { through neuropsychological testing for verbal } \\
\text { comprehension, lexical-semantic system, the } \\
\text { ability to detect semantic relationships, short- } \\
\text { term memory, working memory, and episodic } \\
\text { memory. }\end{array}$ & $\begin{array}{l}\text { The results confirmed the importance of } \\
\text { discourse evaluation and the benefits of } \\
\text { computerized techniques for objective analysis. } \\
\text { Subjects with mild Alzheimer's disease showed } \\
\text { a worse overall performance compared to the } \\
\text { other groups: less discoursive information, } \\
\text { important deterioration in overall coherence, } \\
\text { increase of modularity, and decrease of } \\
\text { narrative structure quality. Also, they often } \\
\text { inserted excerpts from the autobiographical } \\
\text { narrative associating something presented } \\
\text { in the figure with personal experience. The } \\
\text { authors found deficits in verbal comprehension, } \\
\text { working memory, and episodic memory. } \\
\text { Also, they described inserted excerpts of } \\
\text { information to the story pictures associated } \\
\text { with personal experience. } \\
\text { Differences between mild cognitive impairment } \\
\text { and healthy controls were not significant. }\end{array}$ \\
\hline $\begin{array}{l}\text { Serrani -Azcurra } \\
(2012)^{26} \\
\text { Revista Brasileira } \\
\text { Psiquiatria. } \\
\text { Argentina. }\end{array}$ & $\begin{array}{l}\text { To investigate whether a } \\
\text { specific memory program } \\
\text { focused on life history } \\
\text { recounting would be } \\
\text { correlated to a higher } \\
\text { quality of life level in } \\
\text { residents with long-term } \\
\text { dementia. }\end{array}$ & $\begin{array}{l}\text { Simple randomized controlled blind trial with a } \\
\text { sample of } 135 \text { resident with dementia (active } \\
\text { control group = 45; passive control group = } \\
45 ; \text { intervention group = 45) and caregivers. } \\
\text { A life history account was selected as the } \\
\text { intervention procedure for the intervention } \\
\text { group, while the control groups participated in } \\
\text { casual conversations. The social commitment } \\
\text { (SES) and self-reported quality of life (SRQoL) } \\
\text { scales were applied as outcome measures, at } \\
\text { the start of the study (T0), } 12 \text { weeks (T1) and } \\
\text { six months (T2) after the intervention. }\end{array}$ & $\begin{array}{l}\text { The intervention produced significant } \\
\text { differences between the three groups. Over } \\
\text { time, it generated a significant improvement in } \\
\text { the quality of life and in the social commitment } \\
\text { of the residents in the intervention group. One } \\
\text { of the factors attributed to these improvements } \\
\text { were the subtleties observed in the } \\
\text { communication process between subjects and } \\
\text { caregivers associated with increased empathy. }\end{array}$ \\
\hline
\end{tabular}

Figure 3. Characteristics of the selected articles 
the subjects of the experimental group. In addition to the verbal comprehension alterations, the working and episodic memories influenced the process of establishing global significant relations that confer meaning to the discourse. Likewise, the authors emphasized the frequency of insertion of AN information in association with one or another aspect of the story in the experimental group.

The Argentine study ${ }^{26}$ had a sample of 135 subjects (active control group $=45$, passive control group $=$ 45 , and intervention group $=45$ ) and it adpopted a life history account as the intervention procedure, while the control groups participated in casual conversations. Social commitment (SC) and self-reported quality of life (SRQoL) scales were chosen as outcome measures, which were examined at the start of the study (T0), 12 weeks (T1) and six months (T2) after the intervention. The author verified that during shift change activities, which allowed the expression of past memories, subjects were able to play some kind of social role, taking advantage of their preserved skills, and "as a consequence, patients transfer these learned social skills to other activities during their daily relationships with colleagues and staff "(26; p.: 431) (translation by the authors). The intervention program based on life story history produced subtle effects on the communication process because it favored an increase in social activity where communication plays a crucial role. Those aspects are related to the AN discursive context (narrator and interlocutor relationship) which, in turn, plays a fundamental role in the progression of the narrative and constitutes a subject of the development of communication in aging analysis ${ }^{21,27}$.

It is important to note that articles which elected autobiographical narratives as a procedure for the study of other objectives such as memory study, development of reminiscence therapy, specific aspects of psychotherapy approaches, among others, also appeared in the search. Among them are the following: a single case study ${ }^{29}$ of a subject with major NCD, which aimed at studying self-preservation signs within the contents of autobiographical memory; an ethnographic investigation ${ }^{30}$ on the interactive structuring of social life and social interaction categories in daily life activities, among people diagnosed with major NCD and their caregivers; a qualitative study ${ }^{31}$ of subjects with dementia, that explored personal appearance meanings in their lives. The authors verified the importance of narration as a space for the recovery of past sensory experiences in the organization of personal stories; an article ${ }^{32}$ that offered an analysis on how autobiographical memory is related to other forms of memory; a qualitative study ${ }^{33}$ that had the objective of examining whether a therapy that combines reminiscence with productive activity would have a positive effect on elderly patients with dementia, and a study ${ }^{34}$ that explored the impact of cognitive aging on personal memories, working memory and long-term memory, the speed of information processing, the use of processing resources and in the inhibition of unnecessary information.

\section{CONCLUSION}

Literature reviews are essential for the diffusion of health science knowledge, as a source of evidence to support decision-making. Narrating is an important discursive activity that capitalizes communication, cognitive and linguistic skills, and organizes experiences by the use of working memory, episodic memory, and narrative linguistic-discursive processing complex resources. In the context of narrative discourse production, it facilitates the investigation of discursive strategies and narrative activity between the narrator and the interlocutor. After compilation and analyses, the results indicated a limited number of articles related to discursive activities in AN of the older adult presented with neurocognitive disorder.

\section{REFERENCES}

1. Véliz M, Riffo B. Cognitive aging and language processing: relevant issues. RLA. Revista de Lingüística Teórica y Aplicada Concepción. 2010;48(1):75-103.

2. Massi G, Chaves MCM, Wosiacki FT, Paisca A, Lima RR, Tonocchi R et al. Autonomy and participatory aging: a dialogical practice. Rev. CEFAC. 2019;21(6):e14219.

3. López-Álvarez J, Agüera-Ortiz LF. Nuevos criterios diagnósticos de la demencia y la enfermedad de Alzheimer: una visión desde la psicogeriatría. Psicogeriatría. 2015;5(1):3-14.

4. Petersen RC, Caracciolo B, Bravne C, Gauthier S, Jelic V, Fratiglioni L. Mild cognitive Impairment: a concept in evolution. Journal of Internal Medicine. 2014;275(3):214-28.

5. Petersen RC, Roberts RO, Knopman DS, Geda YE, Cha RH, Pankratz VS et al. Prevalence of mild cognitive impairment is higher in men: the Mayo Clinic of Aging. Neurology. 2010;75(10):889-97. 
6. Campbell N, Unverzaqt F, La Mantia M, Khan B, Boustani M. Risk factors for the progression of mild cognitive impairment to dementia. Clinics in Geriatric Medicine. 2013;29(4):873-93.

7. Forlenza OV, Diniz BS, Stella F, Teixeira AL, Gattaz WF. Mild cognitive impairment (part 1): clinical characteristics and predictors of dementia. Braz $\mathrm{J}$ Psychiatry. 2013;35(2):178-85.

8. Cancino $\mathrm{M}$, Rehbein $\mathrm{L}$. Factores de riesgo y precursores del Deterioro Cognitivo Leve (DCL): una mirada sinóptica. Terapia Psicológica. 2016;34(3):183-9.

9. Radanovic M, Stella F, Forlenza OV. Mild cognitive impairment. Rev Med do DC FMUSP. 2015;94(3):162-8.

10. Castillo-Rubén A, De Luna-Castruita JÁ, LópezGarcía R, Pliego-Flores FM, Sánchez-Rubio U, Gallegos EG. Perfil neuropsicológico en enfermedad de Alzheimer, vascular y trastorno frontotemporal. Rev Mex Neuroci. 2014;15(5):259-66.

11. Pop L. Espaces discursifs: pour une représentation d'hétérogénéités discursives. Paris: Éditions Peteers Louvain; 2000.

12. Mac-Kay APMG. Linguagem e Gerontologia. Em: Fernandes F, Mendes B, Navas A (eds). Tratado de Fonoaudiologia. São Paulo,Brasil: Roca. 2010. p.386-91.

13. Figueroa A, Mac-Kay APMG. Narrativas infantis e memória. Revista Pandora Brasil. 2012;44:1-6.

14. Bruner J. A cultura da educação. Trad. Domingues MAG. Porto Alegre: Artmed Editora; 2001.

15. Figueroa Barra A, Mac-Kay APMG, Duran E. Narrative evaluation strategies as metacognitive task in subjects with schizophrenia. CoDAS. 2018;30(3):e20170084.

16. Linde C. Life story: the creation of coherence. Oxford: Oxford University Press;1993.

17. Chessell ZJ, Rathbone CJ, Souchay C, Charlesworth L, Moulin CJA. Autobiographical memory, past and future events, and self-images in younger and older adults. Self and Identity. 2014;13(4):380-97.

18. Salazar MV. Identidad personal y memoria en adultos mayores sin demencia y con enfermedad de Alzheimer. Actualidades en Psicología. 2007;21(108):1-37.

19. Labov W. Padrões Sociolinguísticos. Traduçao Bagno M, Scherre M, Cardoso C. São Paulo: Parábola. 2008.
20. Martinez CS, Noemi C. Conversational reformulation in older adults. Humanidades Medicas. 2017;16(2):227-45 .

21. Mac-Kay APMG, Martínez CS, Figueroa A, Gutierrez $D$, Reyes CS. Análisis de la funcionalidad discursivopragmática en adultos mayores sanos y con demencia leve. Revista Logos. 2018;28(1):192-205.

22. Villar F, Serrat R. El envejecimiento como relato: Una invitación a la gerontología narrativa. Revista Kairós: Gerontologia. 2015;18(2):9-29.

23. Urrútia G, Bonfil X. Declaración PRISMA: una propuesta para mejorar la publicación de revisiones sistemática y metaanálisis. Med Clin. 2010;135(11):507-11.

24. Ahmed S, Irish M, Loane C, Baker I, Husain M, Thompson Butler C. Association between precuneus volumen and autobiographical memory impairment in posterior cortical atrophy: beyond the visual síndrome. Neurolmage Clin. 2018;18:822-34.

25. Toledo CM, Aluísio SM, dos Santos LB, Brucki SMD, Trés ES, de Oliveira MO et al. Analysis of macrolinguistic aspects of narratives from individuals with Alzheimer's disease, mild cognitive impairment, and no cognitive impairment. Alzheimer's \& Dementia. 2018;10:31-40.

26. Serrani-Azcurra DJL. Remenincence program intervention to improve the quality of life of long-term care residents with Alzheimer's disease. A randomized controlled trial. Braz J Psychiatry. 2012;34(4):422-33.

27. Lima TM, Brandão L, Parente MAMP, Peña-Casanova J. Alzheimer's disease: cognition and picture-based narrative discourse. Rev. CEFAC. 2014;16(4):1168-77.

28. Levine B, Svoboda E, Hay JF, Winocur G, Moscovitch M. Aging and autobiographical memory: dissociating episodic from semantic retrieval. Psychology and Aging. 2002;17(4):677-89.

29. Baird AA. reflection on complexity of the self in severe dementia. Cogent Psychology. 2019;6(1):1-5

30. Gjernes T, Måseide P. Framing and scaffolding as relational caregiving in an institution for people living with dementia. Journal of Aging Studies. 2019;49:39-45.

31. Ward R, Cammpbell S, Keady J. Once I had money in my pocket, I was every colour under the sun': using 'appearance biographies' to explore the meanings of appearance for people with dementia. Journal of Aging Studies. 2014;30:64-72. 
32. Janssen S, Kristo G, Rouw R, Murrey J.The relation between verbal and visuospatial memory and autobiographical memory. Consciousness Cogn. 2015;31:12-23.

33. Nakamae T, Yotsumoto K, Tatsumi E, Hashimoto $\mathrm{T}$. Effects of productive activities with reminiscence in occupational therapy for people with dementia: a pilot randomized controlled study. Hong Kong Journal of Occupational Therapy. 2014;24(1):13-9.

34. Bays R. Why does life speed up? The impact of cognitive aging. Procedia - Social and Behavioral Sciences. 2010;2(2):2657-60. 